\title{
Acts and omissions: killing and letting die
}

It is widely assumed in medicine that a doctor must never kill his patient but he may be morally permitted or indeed morally required in certain circumstances to let the patient die (1). The distinction is sometimes seen as a sub-species of a broader distinction which holds that while it may be morally impermissible actively to do something with certain bad results it may none the less be morally permissible to let something happen which has the same bad result. The distinction is sometimes referred to as the 'acts and omissions doctrine' and it seems to be enshrined in medical ethics folklore in A H Clough's satirical line 'thou shalt not kill but need'st not strive officiously to keep alive' (2). It is widely used by doctors to justify withholding life-saving treatment in circumstances in which they would condemn killing a patient but in which they believe the patient's death from natural causes would be morally acceptable. Thus in cases of terminal disease, for instance, life-saving antibiotics or livesaving resuscitation measures are often withheld; and in cases where newborn infants have severe defects such as spina bifida or Down's syndrome, active medical treatment for life-threatening conditions is sometimes withheld. In both types of case, however, active killing would generally be considered morally unacceptable by the doctors concerned. A similar distinction is recognised in English law, which does not permit doctors to kill their patients but does permit them to withhold life-saving treatments in certain circumstances and to administer pain-relieving treatment even in the knowledge that to do so is likely to shorten the patient's life (3).

Philosophers have repeatedly attacked the moral validity of the acts-omission doctrine, especially in the context of killing and letting die. Rachels, for example, in a controversial paper in the New England Fournal of Medicine argued that there was no moral importance in the distinction, that in the context of making life-anddeath decisions it was morally irrelevant, that it could lead to 'patently cruel' results, and finally that the common arguments in support of the moral relevance of the distinction were invalid (4). Rachels is but one of a host of philosophers who have argued against basing life-and-death, moral decisions solely on the distinction between whether a person actively does something which results in another's death or omits to do something, the omission resulting in another's death (5).

Rachels illustrates his moral-irrelevance argument by considering a Down's syndrome baby with 6 duodenal atresia and one without, but otherwise in 은 similar circumstances. Sometimes parents withhold permission for operation on the duodenal obstruction and the infant dies. The reason for withholding the operation is that the child has Down's syndrome 'and $\overrightarrow{0}$ the parents and the doctor judge that because of that fact it is better for the child to die'. On the other hand if the child does not have the duodenal obstruction the child lives on even if the parents and doctors think that it would be better if the child were to die. Rachels calls the situation 'absurd'. If the life of such an infant is worth preserving when it does not have duodenal obstruction then it is worth preserving when it does have duodenal obstruction; conversely if it is judged better that the Down's syndrome infant with duodenal obstruction should die then the same judgement should be made about the unobstructed Down's syndrome infant; 'what difference does it make that it happens to have an unobstructed intestinal tract? In either case the matter of life and death is being decided on irrelevant grounds'.

Rachels supports his argument that the distinction is not in itself of moral importance by postulating two cases exactly alike except in the fact that one involves a killing and the other a letting die. Thus Smith, standing to gain a fortune from the death of his sixyear-old cousin, surreptitiously drowns the boy in the bath, and makes it look like an accident. Jones who also stands to gain a fortune from the death of his cousin sneaks into the bathroom intent to drown the boy but sees the child slip, bang his head, fall unconscious and drown. Jones waits to make sure he dies, ready to push the boy under if he wakes, but he drowns accidentally. Clearly, argues Rachels, the only difference built into the examples is that in one a man killed his six-year-old cousin and in the other he 'merely' let his cousin die. In the absence of further distinctions between the two $\triangle$ cases there is no plausible basis for finding Jones less morally culpable than Smith or for finding any moral 8 distinction between the case of killing and the case of letting die. Therefore the difference between killing and letting die can not be, in itself, of moral relevance. 
Rachels supports his claim that the use of the killingletting die distinction can lead to cruelty by citing a paediatrician's account of what happens when it is decided to let a severely handicapped infant die. The doctor 'must try to keep the infant from suffering while natural forces sap the baby's life away' - it is a 'terrible ordeal' to stand by 'and watch as dehydration and infection wither a tiny being over hours and days'. Having quoted this harrowing account Rachels writes 'The doctrine that says that a baby may be allowed to dehydrate and wither, but may not be given an injection that would end its life without suffering, seems so patently cruel as to require no further refutation'.

This last argument is surely too weak - the power of contemporary medicine to control pain is sufficient to ensure that patients being allowed to die do not suffer and the paediatrician indicates that the child was not suffering. Of course, given normal fallibility, undoubtedly patients as a whole will suffer more if they are allowed to die than if they are killed - and clearly there is considerable suffering amongst staff and relatives when patients are allowed to die. It is not clear, however, that there would be less suffering if the patients were instead killed. Rachel's other arguments, however, do seem to deal a powerful blow to the actsomissions doctrine as illustrated by the distinction between killing and letting die.

One common argument in support of the doctrine is that in letting a patient die a doctor does not do anything to cause the patient's death - it is the disease process which causes the patient's death - it is nature taking its course (6). There are at least two problems with this line of argument. The first concerns the nature of action. While it may be arguable that if a person does not move he is not acting in the sense of being active (and even that claim is dubious), a person who intentionally takes no action may none the less be acting, in the morally important sense of human agency. The action he takes in that sense of action, and under one description, is intentionally to allow his patient to die. The fact that he did so by avoiding certain physical actions is not in itself morally exonerating - there are countless situations in which it is clearly morally reprehensible to take no action with the intention of allowing another person to die, particularly so if that person is one's patient. Similarly the argument that one is allowing nature to take its course is of no moral weight, for there are countless circumstances in which allowing nature to take its course is morally reprehensible (allowing the diabetic to die of coma in the casualty department is allowing nature to take its course - but, of course, the doctor's job in these and many other circumstances is precisely to stop nature taking its course).

As Anne Slack points out in this issue of the journal (7) the acts-omissions doctrine is particularly criticised by utilitarian writers and while their arguments that the bare distinction between acts and omissions is of no moral significance seem impregnable none the less some features often associated with the acts-omissions distinction are of moral significance and may help to differentiate morally valid aspects of the acts-omissions intuition from morally irrelevant or unacceptable aspects.

The first feature is that there are good utilitarian grounds for distinguishing between killing and letting die and for blaming and punishing those who kill more than those who merely let die. The plain fact is that it is much easier to stop people killing others than to stop them letting others die. Given that there are strong utilitarian grounds for keeping people alive and that it is relatively easy to stop people killing each other and exceedingly difficult to stop them allowing each other to die there seem to be good utilitarian grounds for social institutions which create a general (though defeasible) moral prohibition against killing while having only a relatively weak injunction against people being allowed to die. Similar but increasingly powerful utilitarian reasoning would support such a distinction in the context of medical practice: the fear of being killed would be enormously magnified in the absence of a general medical prohibition against killing; patients are by definition particularly vulnerable and doctors particularly powerful. Conversely a very strong prohibition against allowing to die would, in modern times, be markedly welfare-reducing, for medicine's ever increasing ability to hold up people's deaths would, if encouraged to flourish untrammelled, swallow up available resources to the detriment of overall welfare. Thus while the acts-omissions doctrine cannot be defended by utilitarians as being a morally valid principle, its social institutionalisation might be defensible as a welfare-maximising rule of thumb.

For non-utilitarians other defences of principles akin to the acts-omissions doctrine may be available. Absolutist deontologists for example might follow the Roman Catholic tradition and claim that intentional killing of innocent persons was always morally forbidden, whatever the consequences, while omissions which result in the death of innocent persons may be morally permissible if (a) the death while foreseen is not intended and (b) in not preventing the death one is not failing to do something one has a moral duty to do (8). Certainly there are problems for this position, especially for those who reject the absolutist premise; certainly too this distinction is not based on the bare acts-omissions distinction criticised above. However, it does afford an arguable basis for defending something similar.

Finally it may be that the principles of nonmaleficence and respect for autonomy also generate distinctions akin to the acts-omissions doctrine. Thus both may arguably be better fulfilled in practice by concentrating on prohibiting certain positive actions (those that harm or interfere with the autonomy of others) than by concern to avoid the infinite range of omissions which may have similar effects. In the case of

(Continued on page 72) 


\section{Questionnaire on ethics and the severely malformed infant}

1. Which of the following infants do you think should be treated intensively, even against the parents' wishes?

a) Spina bifida with hydrocephalus and large spinal defect

b) Down's syndrome with duodenal atresia

c) Severely premature baby with lung disease, mother wanted abortion but too late

d) Rhesus baby of Jehovah's Witness needing exchange blood transfusion

e) Baby of a narcotic addict with withdrawal syndrome

1.i On what grounds did you come to your decision?

2. Who should be present routinely when a paediatrician first discusses the defects of a severely malformed baby with mother?
a) Father of baby
e) Health visitor
b) Mother's mother/father
f) Priest
c) Nurse/midwife
g) Social worker
d) GP
h) Lawyer

2.i Who should make the decision?

3. Should a parent be able to sue a health authority following the birth of an abnormal baby if screening tests were not offered?

$\mathbf{Y} / \mathbf{N}$

4. If another defect (possibly harmless) is discovered at amniocentesis, should the parents be told?

5. If a severely affected baby is not being treated intensively, which of the following regimes are justified?
a) Increasing doses of sedative/analgesic
$\mathrm{Y} / \mathrm{N}$
b) Water feeds only
c) Milk feeds on demand
$\mathrm{Y} / \mathrm{N}$
d) Regular milk, including tube feeds
$\mathrm{Y} / \mathrm{N}$
e) Antibiotics
$\mathrm{Y} / \mathrm{N}$
f) Ventilator support
$\mathrm{Y} / \mathrm{N}$
$\mathrm{Y} / \mathrm{N}$

(Continued from page 60)

respect for autonomy this may be linked to the fact that actions require time and energy and thus are a greater intrusion upon the autonomy of the agent than are omissions which in general require less time and energy. Once again such a distinction, even if supportable, does not support the bare acts-omissions doctrine - but it does indicate a similar and potentially morally relevant distinction.

The practice of treating killing and letting die as being of intrinsic moral difference can thus not be based on the bare difference between acts and omissions. However, a variety of other moral considerations - utilitarian welfare maximisation, Roman Catholic absolutism, and the principles of nonmaleficence and respect for autonomy - can be adduced to justify social practices not unlike those that result from the 'bare' doctrine of acts and omissions.

\section{References and notes}

(1) See for example British Medical Association. The handbook of medical ethics. London: BMA, 1981: 34-35.

(2) Clough A H. The latest decalogue. Quoted in Glover J. Causing death and saving lives. Harmondsworth: Penguin, 1977: 92.

(3) Mason J K, McCall-Smith A. Law and medical ethics. London: Butterworths, 1983: 178-189.

(4) Rachels J. Active and passive euthanasia. New England medical journal 1975; 292: 78-80. Reprinted: See reference (5).

(5) Steinbock B, ed. Killing and letting die. Englewood Cliffs: Prentice Hall, 1980. An excellent collection.

(6) An argument referred to neutrally in the BMA handbook. See reference (1): 35 .

(7) Slack A. Killing and allowing to die in medical practice. fournal of medical ethics 1984; 10: 82-87.

(8) The Linacre Centre. Is there a morally significant difference between killing and letting die? In: Prolongation of life. London: The Linacre Centre, 1978: 7-10. 